\title{
INFLUENCE OF DAMAGED GROINS ON NOURISHED SEASHORE
}

\author{
Ostrowski R ${ }^{1}$, Pruszak Z. ${ }^{1}$, Schönhofer J. ${ }^{1}$, Szmytkiewicz M. ${ }^{1}$, Szmytkiewicz P. ${ }^{1}$
}

\begin{abstract}
The system of timber palisade groins can be very helpful as a measure coexisting with artificial nourishment and increasing the lifetime of beach fills. To this end, good condition of groins and their permanent contact with land is necessary. On the basis of theoretical modelling and field surveys a conclusion has been formulated that coexistence of complete groins with artificial shore nourishment causes that about $30 \%$ less sediment is washed away from the nearshore zone than for beach fill without groins.
\end{abstract}

Keywords: groins, beach nourishment, erosion, field survey, optimization

\section{INTRODUCTION}

The erosion trends in Poland keep the attention to shore protection, which is intended to defend economically important dunes and cliffs, together with low agricultural lands adjacent to the sea, including river mouths. Various technological means are used to achieve this goal, viz: (1) acceleration of natural growth of dunes and their stabilization using grass, bushes, trees and fascine, (2) artificial beach nourishment, (3) construction and reinforcement of flood dikes, (4) construction of shore protection systems employing groins, revetments, fascine and stone seawalls, etc. All these measures interfere with the natural coastal phenomena and affect considerably the transformation of coastline not only at places of man's direct impact but also in adjacent areas. The first coastal groins, $40 \mathrm{~m}$ long and spaced every 50-70 m, were driven at several locations in the years 1873-1874 (Basiński and Żmudziński 1983). Despite of continuous improvement in knowledge concerning groins effectiveness, a decision on their application is always difficult. There are coastal segments where positive effects of groins are clearly visible and there are shores where groins have proved to be inefficient or even harmful. The south Baltic groins, including the ones existing on the Polish coast are mostly the singlerow palisade structures, built of timber piles. Such groins can be permeable or impermeable. The permeable groins are generally said to be more efficient: they reduce the longshore fluxes of water and sediment improving conditions for accumulation of sand in fields between the groins and they reduce the lee-side erosion effect, while the impermeable groins cause distinctly inconvenient increase of longshore current velocities nearby the groins tips and strong flows along the structures, both of which result in appearance of deep scour holes. Optimisation of the groin permeability is a challenge for coastal engineers, yielding the quantity considerably dependent on local conditions. In Poland, the obtained optimal permeability values lie around $30 \%$ which is in agreement with the German experience. The existing groins lengths amount to $40-100 \mathrm{~m}, 27 \%$ of which have lengths of $61-80 \mathrm{~m}$ and $26 \%$ the lengths of $81-100 \mathrm{~m}$. It is a general rule that crests of the groins are elevated by $0.5 \mathrm{~m}$ above the mean sea level. Within an individual system of groins, spaces between them are usually equal to about $100 \mathrm{~m}$. Due to their age, many groins along the Polish coast are damaged and malfunctioning. A lack of single piles in a structure does not have a significant influence on the groin effectiveness as it just locally increases its permeability, while a breach comprising 2 and more piles results in increase of current velocities in the structure segment where piles are missing. This causes scours and decrease the accumulative action of the groin.

The groins are found along almost entire Polish open sea shore, but they are presently rebuilt or built as the new ones only in the central part of the Polish coast which is managed by the Maritime Office in Słupsk. Recently, also the Inspectorate of Coastal Protection subject to the Maritime Office in Gdynia (responsible for management of the east part of the Polish coast) considers renovation of the groin system along Hel Peninsula. In 2011, intensive studies were carried out by the Institute of HydroEngineering of the Polish Academy of Sciences (IBW PAN) to clarify whether this will improve the effectiveness of artificial beach nourishment carried out on Hel Peninsula shores.

The investigations described below have been carried out in order to assess influence of breaches in a groin structure on hydrodynamics around groins. The study concerns a groin system, stretching along a $10 \mathrm{~km}$ long shore segment on Hel Peninsula (Poland), including interaction of these groins with hydro- and morphodynamic coastal processes. On Hel Peninsula lightweight stone-and-fascine

\footnotetext{
${ }^{1}$ Institute of Hydro-Engineering of the Polish Academy of Sciences (IBW PAN), Kościerska 7, 80-328 Gdańsk,
} Poland 
revetments constructed in 1936 were totally destroyed after short time. A group of 44 groins was constructed near the port of Władysławowo in the years 1946-48 as timber palisades, each about $60 \mathrm{~m}$ long, spaced from each other by about $90 \mathrm{~m}$, together with another group of 11 driven in 1948 about 4 $\mathrm{km}$ downdrift of the previous groins. Some other erosion areas were also protected with groins but the erosion phenomena at the extremes of the groin groups again occurred. In the course of this continuous construction of new groins a $13 \mathrm{~km}$ long section of Hel Peninsula was much reshaped. However, the shore was destroyed seriously during the winter storms of 1983. The nourishment has been carried out since then and successfully stopped the erosion at the site. The groins, coexisting with artificial beach fills, are subject to gradual damage manifested by loss of piles at various sections of the structures. The present work has been focused on the analysis of influence of the groins damage on their usefulness and coexistence with the shore nourishment. Four cases have been considered: the complete groin and the groins with three kinds of missing piles. These cases are illustrated in Fig. 1.
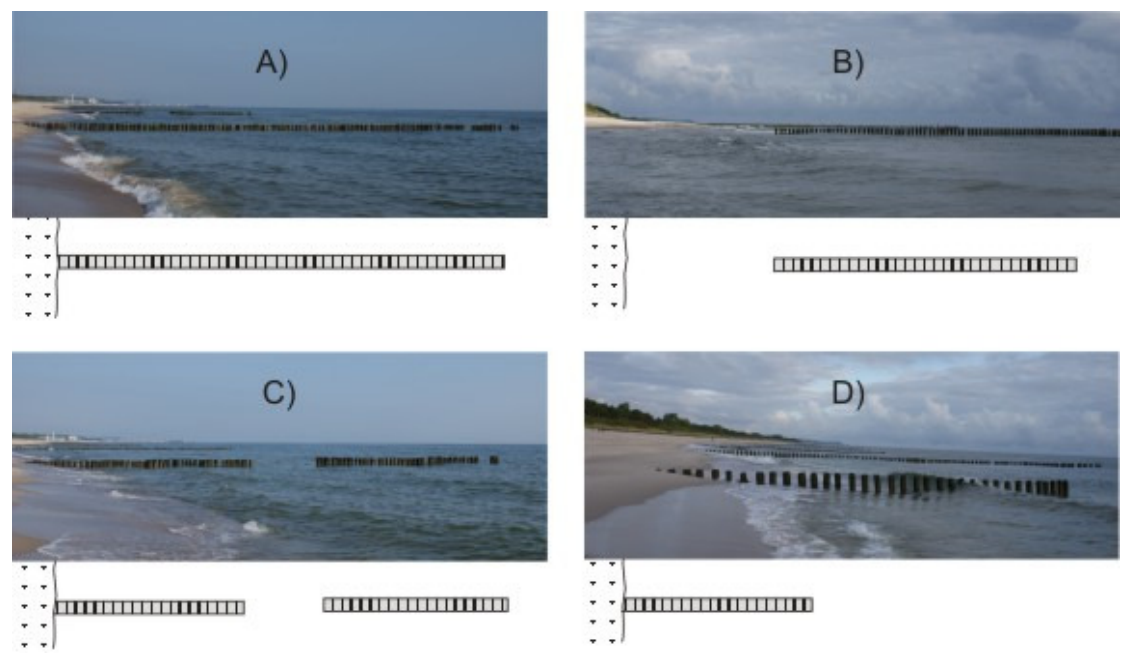

Figure 1. Kinds of groin malfunction: A) complete groin, B) groin separated from shoreline, C) missing piles about groin central part, D) missing piles in groin end

\section{COMPUTATIONAL RESULTS}

The study has been based on field observations and numerical modelling using Delft3D software. It was assumed that the shore was subject to artificial nourishment, as shown in Fig. 2. The computations yielded parameters of waves and currents in the fields between groins, as well as sediment transport rates and bathymetric changes.

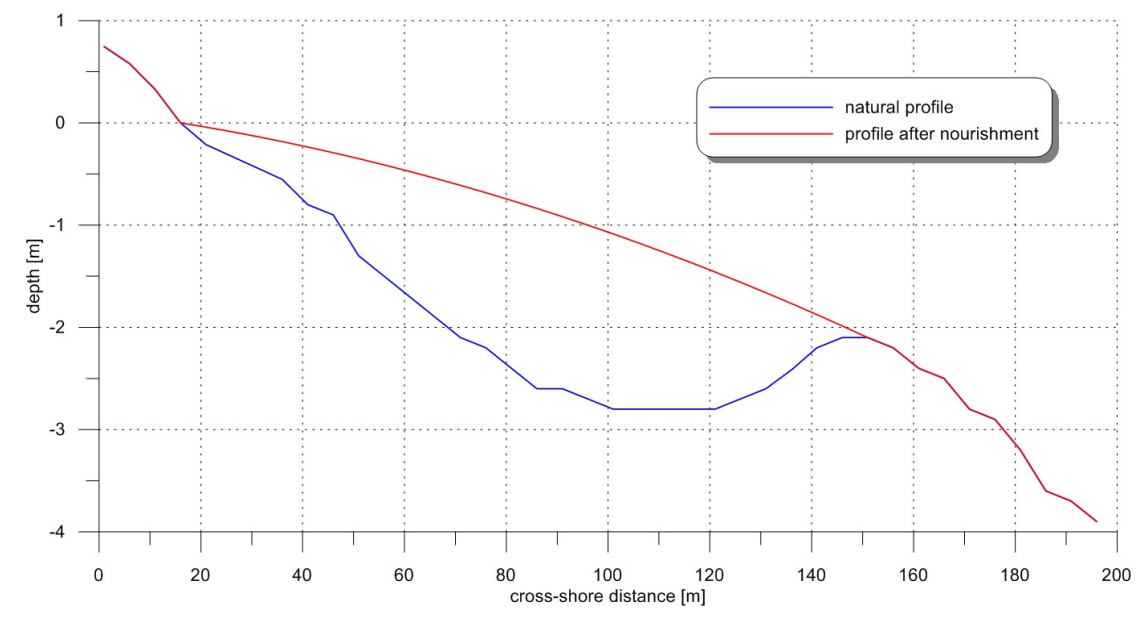

Figure 2. Cross-shore profile assumed in modelling of erosion of nourished shore with groins and without groins 
All four cases of technical condition of groins (as illustrated in Fig 1) were considered. The results of modelling of flow velocities for these cases are shown in Figures 3-6.
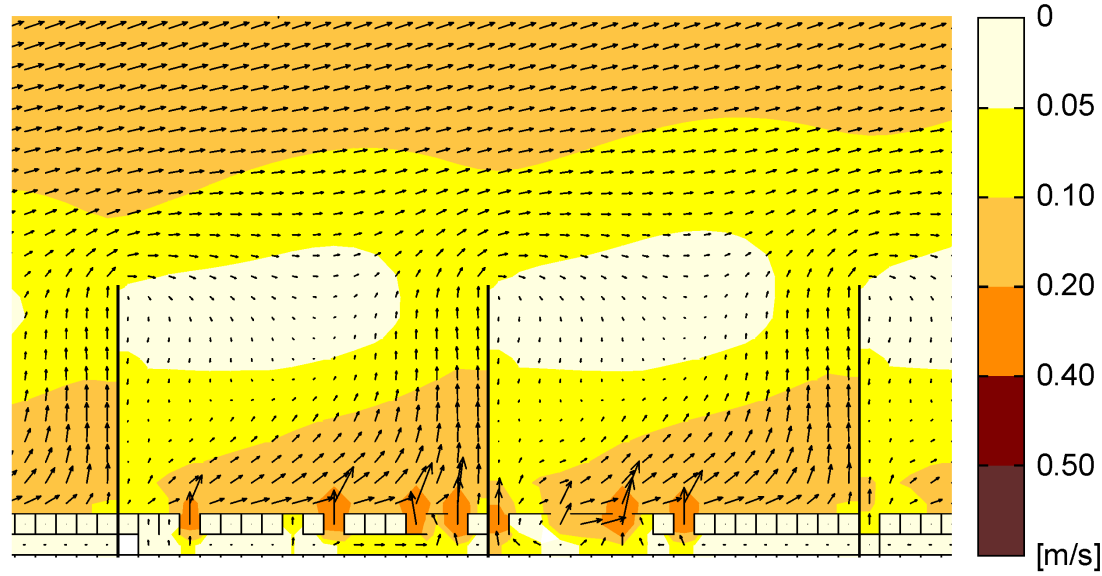

Figure 3. Current velocities around complete groins (case A)

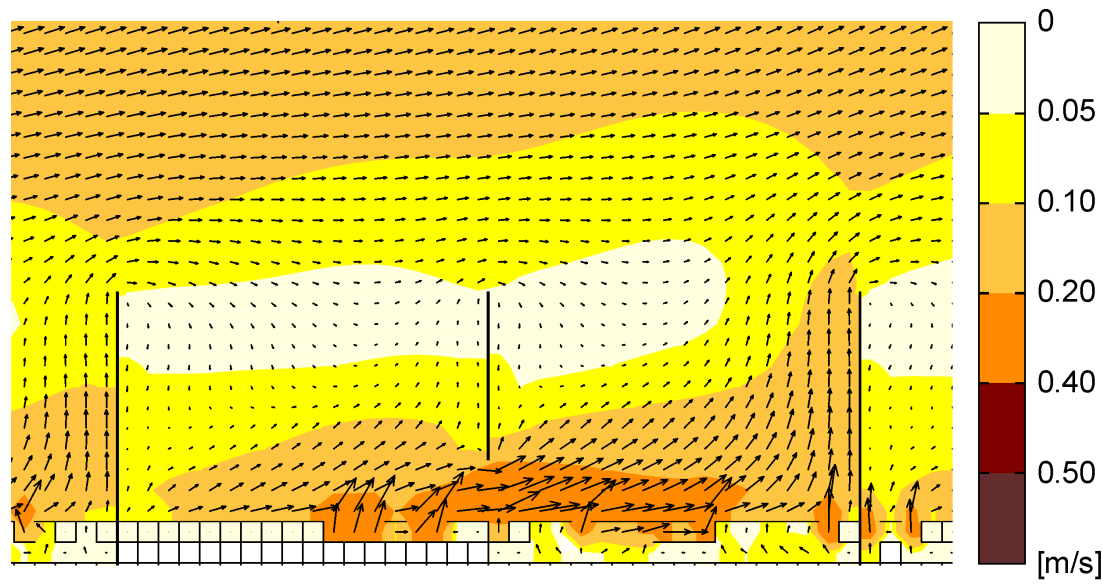

Figure 4. Increased current velocities in breach at root part of groin (case B)

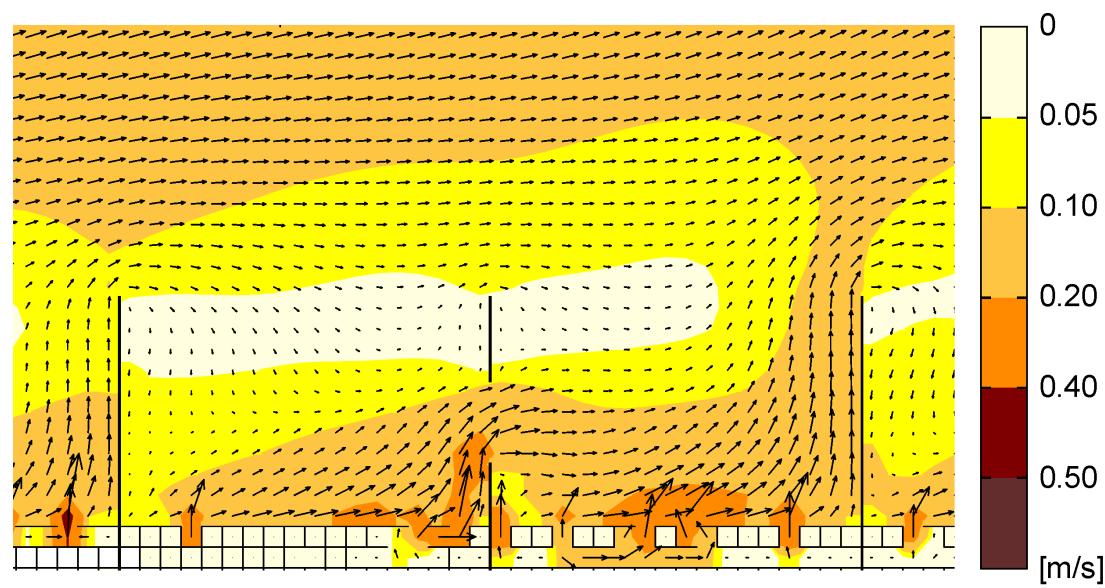

Figure 5. Increased current velocities in breach about middle of groin (case C) 


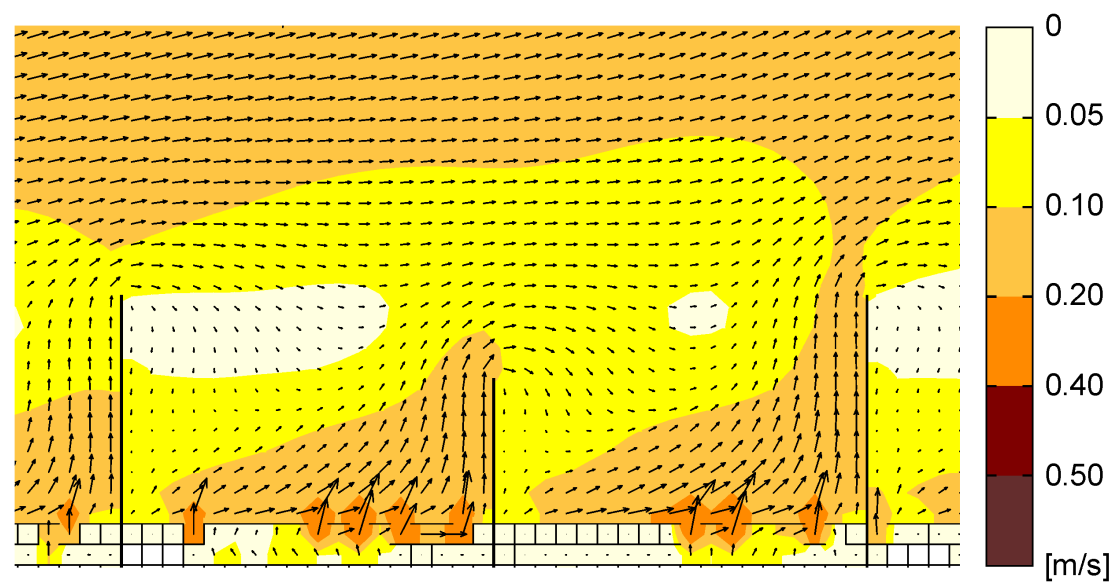

Figure 6. Current velocities in case of missing piles in groin end (case D)

A breach between a groin and the shoreline (case B) produces the most adverse effect for the artificial beach fill as it results in intensification of erosion due to generation of an additional, strong nearshore current. If the breach exists about the middle of the groin (case $\mathrm{C}$ ) the strong current causes local erosion near this breach. This case is less dangerous than case B. If the end piles of a groin are missing (case D) the supporting role of the groin to the beach fill is smaller than in case A. The adverse effects are not that severe as in cases B and C.

The quantitative determination of the influence of complete groins on the lifetime of artificial shore nourishment was achieved by mathematical modelling of seabed morphodynamics within the area delineated by three neighbouring groins. The computational procedure is described below.

1. Modelling of sediment transport and nearshore morphodynamics (bathymetric changes in two neighbouring fields between three groins).

2. Determination of volume of sediment washed away from the considered area, namely: $60 \mathrm{~m}$ (groin length) $\times 2$ (fields) $\times 90$ (distance between groins) $=10800 \mathrm{~m}^{2}$.

3. Modelling of sediment transport and nearshore morphodynamics in the respective area $\left(10800 \mathrm{~m}^{2}\right)$ for the natural shore (without groins).

4. Determination of volume of sediment washed away from the respective area $\left(10800 \mathrm{~m}^{2}\right)$

5. Calculation of coefficient $W$ :

$$
W=\left(1-\frac{V_{\text {groins }}}{V_{\text {natural }}}\right) \cdot 100 \%
$$

where $V_{\text {groins }}$ is nourishment volume washed away from the area covered by 3 groins ( 2 neighbouring fields) and $V_{\text {natural }}$ nourishment volume washed away from the respective area for the natural shore.

The results of modelling of nearshore morphodynamics (sea bed changes) for 3 sets of wave conditions are shown in Figures 7-9. 

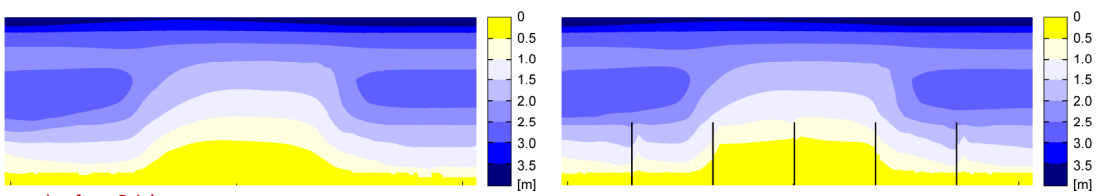

a) after 24 hours
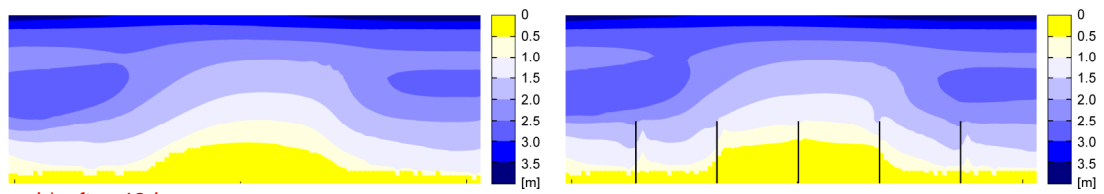

b) after 48 hours
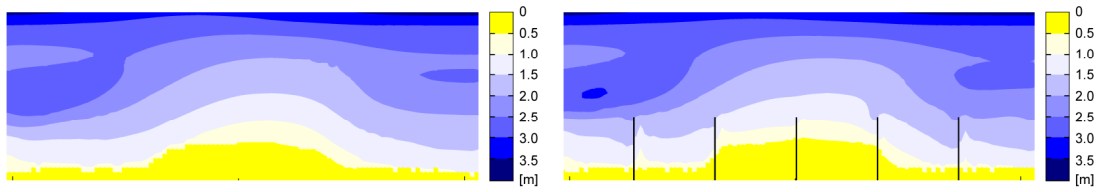

c) after 72 hours
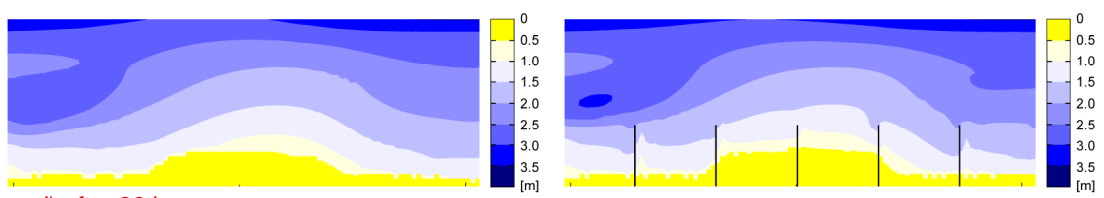

d) after 96 hours

Figure 7. Results of numerical simulations of bathymetric changes for natural shore and shore with groins for weak wave conditions. Wave parameters $1.2 \mathrm{~km}$ offshore (wave approach $45^{\circ}$ from left): $H_{s}=1.0 \mathrm{~m}, T_{p}=$ $4.0 \mathrm{~s}$

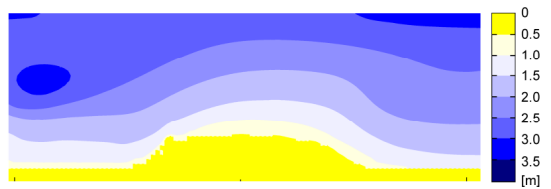

a) after 24 hours

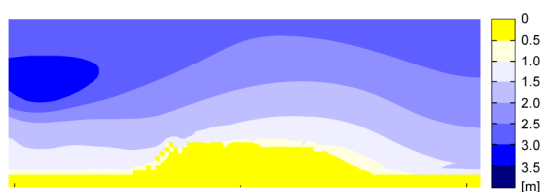

b) after 48 hours

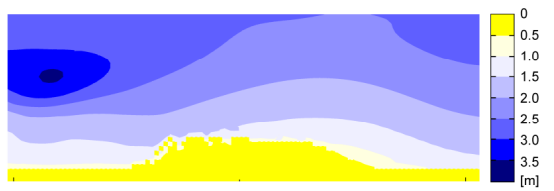

c) after 72 hours

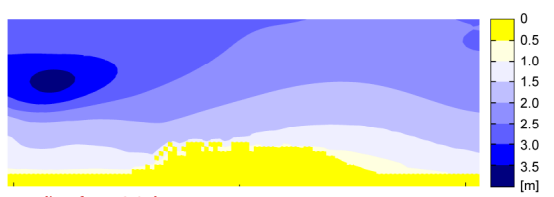

d) after 96 hours
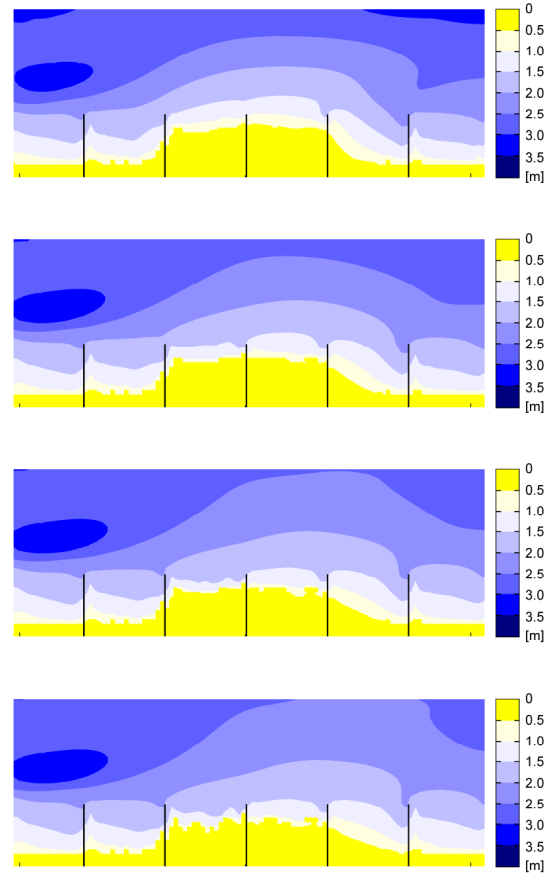

Figure 8. Results of numerical simulations of bathymetric changes for natural shore and shore with groins for moderate wave conditions. Wave parameters $1.2 \mathrm{~km}$ offshore (wave approach $45^{\circ}$ from left): $H_{s}=1.5 \mathrm{~m}$, $T_{p}=5.5 \mathrm{~s}$ 


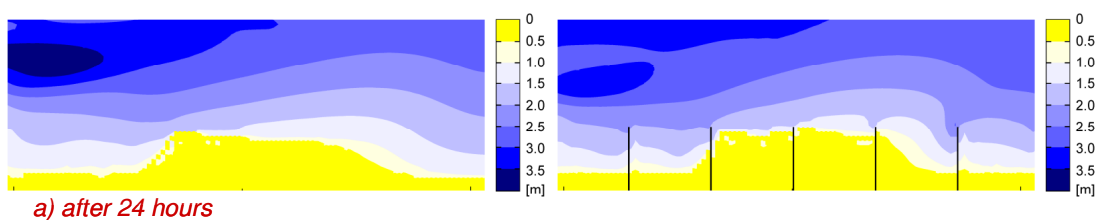

a) after 24 hours
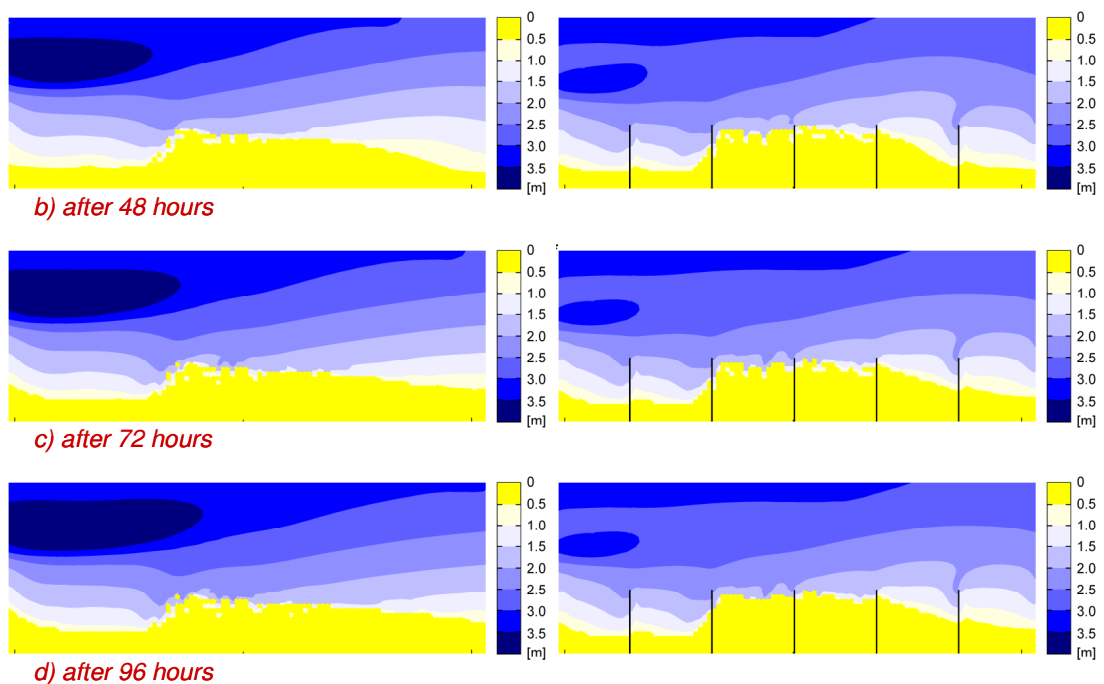

Figure 9. Results of numerical simulations of bathymetric changes for natural shore and shore with groins for severe wave conditions. Wave parameters $1.2 \mathrm{~km}$ offshore (wave approach $45^{\circ}$ from left): $H_{s}=2.0 \mathrm{~m}$, $T_{p}=7.0 \mathrm{~s}$

The results of computations of the coefficient $W$ are depicted in Fig. 10. The value $W=0$ means that no supporting role of groins can be expected while $W=100 \%$ denotes the fully effective support of groins.

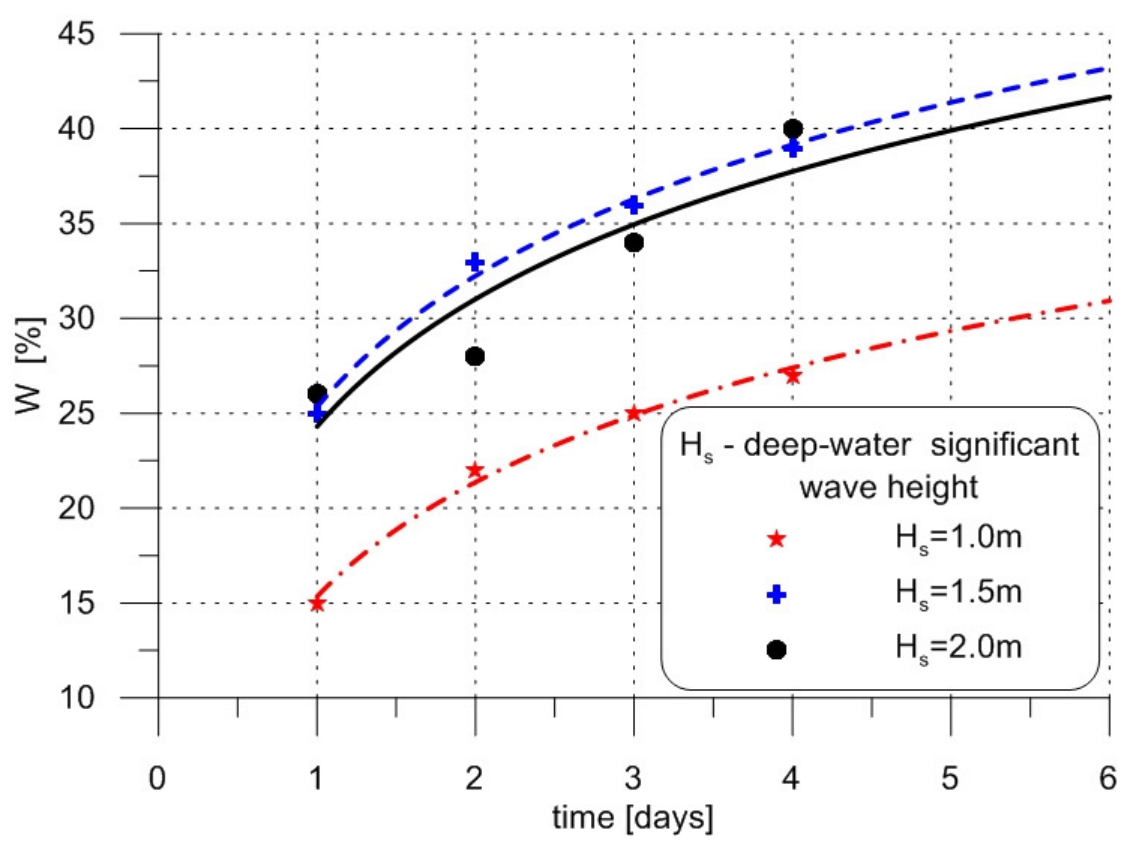

\section{Figure 10. Coefficient $\mathrm{W}$ as function of time}

It can be seen from Fig. 10 that coexistence of complete groins with artificial beach nourishment (case A of Fig. 1) causes that less sediment is washed away from the nearshore zone (calculated as a coefficient $W$, after 6 days amounting to about 30-45\%, depending on wave height) than for beach fill without groins. 


\section{CONCLUSIONS}

Artificial shore nourishment is the basic method of coastal erosion mitigation on the open sea sandy coast of Hel Peninsula. At most threatened and important shore segments, gabion revetments are built into dunes. These additional measures (invisible in normal conditions) constitute the second line of defence which becomes active when the beach and dunes are eroded under the impact of storm waves. After the storm, the dunes are re-nourished and their original shape is restored.

The system of timber palisade groins can be very helpful as a measure coexisting with artificial nourishment and increasing the lifetime of beach fills. To this end, good condition of groins and their permanent contact with land is necessary. On the basis of theoretical modelling and field surveys, the following detailed conclusions have been drawn.

- Total reconstruction of the entire groin system on the shore segment $12 \mathrm{~km}$ long (where the groins were originally built) is not recommended at the moment. Renovation of the groin system on the first $10 \mathrm{~km}$ long segment from the root of Hel Peninsula is necessary. This renovation can be carried out by stages.

- The groins no. 2 - no. 12 (0.11-1.02 km from Hel Peninsula root), being in bad or very bad condition, should be rebuilt or constructed as new ones close (several metres) to the remnants of the old malfunctioning groins. The new groins ought to have a permeability of $30 \%$. The remnants of the old groins will have no influence on the shore - they can be removed because of aesthetical reasons or due to safety of swimmers.

- The following groins should be renovated: no. 21 (1.86 km from Hel Peninsula root), no. 40-41 $(3.75-3.93 \mathrm{~km})$, no. $58-59(5.36-5.40 \mathrm{~km})$ and no. 76-80 $(6.99-7.39 \mathrm{~km})$. The renovation works should comprise the breaches where 5 or more piles are missing. Two groins about $5.4 \mathrm{~km}$ should be elongated seawards.

- Along the shore segment located from $3.6 \mathrm{~km}$ to $4.0 \mathrm{~km}$ from the root of Hel Peninsula, distances between the groins are twice bigger than elsewhere. There are 4 gaps of this kind which should be filled in by additional 4 groins.

- At the end of the groin system (groins no. 109-114, located 9.97-10.2 km from Hel Peninsula root), the groins ought to be elongated landwards so that they have gain a contact with the shore. Breaches existing in a part of them should be filled in by timber piles.

- The erosive area on the lee side of the groin system (10.2 km and more from Hel Peninsula) imposes a necessity of frequent re-nourishment of the shore. This region should be subject to thorough monitoring. Results of the investigations will be helpful in possible future considerations on effectiveness of the longshore extension of the groin system in SE direction.

\section{GENERAL RECOMMENDATIONS CONCERNING DAMAGED GROINS}

It appears from both field surveys and theoretical modelling that breaches in groins generate negative hydrodynamic and morphodynamic effects in the nearshore zone. These effects can particularly be harmful if the shore is artificially nourished by sandy sediments. Besides, observations have revealed a considerable influence of gaps within a groin system. On the basis of the above investigations the following conclusions and recommendations for the non-tidal shores have been formulated.

- In many cases, where sediment deficit takes place, groins as the only measure are (or become) ineffective and should not be applied. Groins can be, however, recommended as the measures supporting artificial shore nourishment.

- Within a system of groins, where gaps between the groins are much bigger than groins length, severe shore erosion is frequently observed. Additional groins constructed at such locations are likely to mitigate the problem.

- Lack of single piles in the palisade groin does affect its efficiency, while wider breaches, comprising a few piles, result in appearance (or growth, in case of permeable structures) of flow velocities through the groin. This in turn causes intensive sea bed erosion at the breaches. Groins with breaches near the shoreline are very harmful because of resulting severe erosion close to the shoreline.

- For weak/moderate conditions (with the offshore wave height $\mathrm{Hs} \approx 1 \mathrm{~m}$ ) the flow velocities between (undamaged) groins lie below those for no-groins case and are smaller than the velocities generating the mass motion of sediment. 
- The groins tips should reach the first bar, particularly for the artificially nourished shore. If sufficiently long and in good technical condition, the groins increase lifetime of the beach fills and improve the shore stability. Coexistence of complete groins with artificial shore nourishment causes that about $30 \%$ less sediment is washed away from the nearshore zone than for beach fill without groins.

\section{ACKNOWLEDGMENTS}

The support of the European Commission through FP7.2009-1, contract 244104 - THESEUS ("Innovative technologies for safer European coasts in a changing climate"), is gratefully acknowledged. The study was cosponsored by the Ministry of Science and Higher Education, Poland, under the IBW PAN statutory programme No. 2.

\section{REFERENCES}

Basiński T., Żmudziński L. 1983. Natural conditions and man-induced changes in the Polish coast of the Baltic Sea, Gdańsk: IBW PAN

Kaczmarek L. M., Ostrowski R. 2002. Modelling intensive near-bed sand transport under wave-current flow versus laboratory and field data, Coastal Engineering, Vol. 45, No. 1, 1-18

Pruszak Z., Szmytkiewicz P., Ostrowski R., Skaja M., Szmytkiewicz M. 2008. Shallow-water wave energy in a multi-bar coastal zone, Oceanologia, Vol. 50, No. 1, 43-58

Szmytkiewicz M., Biegowski J., Kaczmarek L. M., Okrój T., Ostrowski R., Pruszak Z., Różyński G., Skaja M. 2000. Coastline changes nearby harbour structures: comparative analysis of one-line models versus field data, Coastal Engineering, Vol. 40, $n r$ 2, 119-139

Szmytkiewicz M., Zeidler R. B., Różyński G., Skaja M. 1998. Modelling large-scale dynamics of Hel Peninsula, Proceedings of Coastal Engineering 1998, Vol. 3. Red. Billy L. Edge, Reston: ASCE, 2837-2850 